\title{
Chinese female nursing students' coping strategies, self-esteem and related factors in different years of school
}

\author{
Chunping $\mathrm{Ni}^{1}$, Daiwei $\mathrm{Lo}^{2}$, Xiwen Liu ${ }^{1}$, Qun Yang ${ }^{1}$, Jinfeng $\mathrm{Ma}^{1}$, Shasha $\mathrm{Xu}^{1}, \mathrm{Lu} \mathrm{Li}^{3}$ \\ 1. Faculty of Nursing, Fourth Military Medical University, Shaanxi Province, China. 2. Nationwide Children's Hospital, 700 \\ Children's Drive Columbus, Ohio, U.S.A. 3. Department of Political Theories Teaching-research, Fourth Military Medical \\ University, Shaanxi Province, China
}

Correspondence: Shasha Xu, Lu Li. Address: Fourth Military Medical University, 169 Changlexi street, Xi'an, Shaanxi Province 710032, People's Republic of China. Telephone: 86-298-477-4894. Email: shali50084@163.com

Received: March 7, 2012

Accepted: March 29, $2012 \quad$ Published: November 1, 2012

DOI : $10.5430 /$ jnep.v2n4p33

URL: http://dx.doi.org/10.5430/jnep.v2n4p33

\section{Abstract}

Background: Recent research has emphasized the importance of coping. There is virtually nothing known about coping strategies and their relationship with self-esteem, individual and environmental factors among Chinese female nursing students. This study was to identify different coping strategies, the relationship between coping and self-esteem and influencing individual factors among Chinese female students in different years of nursing school.

Method: The study used a cross-sectional design. A representative sample composed of 686 female nursing students aged 14 years or older was surveyed in December 2010 using the Simplified Coping Styles Questionnaire, the Self-Esteem Scale and the Personal Data Form for assessment.

Results: Nursing students more often used positive rather than negative coping styles $(P<0.001)$. There was significant difference in the positive coping between nursing students in different years of school ( $P=0.018$ ). The positive coping style was significantly correlated to a higher level of self-esteem, good interpersonal relationships, enough free time for study alone, a sense of self-fulfillment and satisfaction, adaptation to new study methods, close friendships, help-seeking behavior of an individual, and physical health in the past year $(P<0.05)$. The negative coping style was significantly associated with problems in romantic relationship, relationship with parents, worry about examinations and job assignment after graduation, feeling misunderstood, and frequent surfing on the internet $(P<0.05)$.

Conclusion: There were different coping strategies and the important relationship between self-esteem, individual and environmental factors and coping strategies among Chinese female nursing students in different years of school. The teaching strategies that promote the self-esteem and pay more attention to students' individual and environmental factors will be useful for helping nursing students develop effective coping styles.

\section{Key words}

Coping strategy, Nursing students, Self-esteem, Individual factors, Environmental factors 


\section{Introduction}

Coping is considered an important buffer in the relationship between stress and illness ${ }^{[1]}$. Recent research has emphasized the importance of coping. Early typologies of coping identified three main categories: problem-focused coping, avoidance-focused coping and emotion-focused coping ${ }^{[2,3]}$. In China, coping styles were usually classified into two dimensions: positive and negative coping. These two coping styles focused on problem-resolved and problem-avoided aspects, respectively. Studies of coping with stressful situations showed that negative coping was associated with more psychological problems while positive coping may prevent burnout ${ }^{[4,5]}$.

The nursing school years are an important period of transition from adolescents to trained nurses. The personal coping style developed during adolescence can determine the coping style employed in adulthood ${ }^{[2]}$. Nursing students should develop effective coping strategies to handle new stressors. In China, nursing students are predominantly female, a special adolescent group. Earlier studies reported that females more often endorsed an emotion-focused than problem-focused coping style ${ }^{[6]}$ and they seek more social support ${ }^{[4,7]}$. These earlier studies, however, did not examine whether coping strategies differed among nursing students in different years of nursing school. Understanding the coping strategies of this particular population in different years of nursing school has been identified as an area of important study, and one that is important to the training of them.

According to the Morris Rosenberg Foundation ${ }^{[8]}$, "Self-esteem is a positive or negative orientation toward oneself; an overall evaluation of one's worth or value”. Historically, self-esteem has been identified as an important predictor of adjustment to stress. Higher levels of self-esteem have been associated with positive characteristics such as initiative, persistence in the face of challenges, happiness and longevity. Furthermore, higher levels of self-esteem are associated with increased self-efficacy, body image and leadership, and reduced frequency of depression and anxiety ${ }^{[9-12]}$. Adequate coping in adolescents has been reported to predict higher levels of self-esteem ${ }^{[13]}$. There have been some debates of the construct of self-esteem in Eastern and Western cultures. However, little is known about the relationship between self-esteem and coping styles among Chinese nursing students in Eastern cultures.

In previous studies, certain individual characteristics have been reported to relate to coping strategies. For example, age and gender are considered to be crucial variables affecting coping strategies ${ }^{[14]}$. Other factors, such as demographic, cultural and environmental factors have been presumed to influence individuals' coping styles ${ }^{[15]}$. Although research in Europe, America and Oceania have identified a variety of workplace stressors and coping strategies of nurses, there is a lack of research addressing these factors in the nursing students ${ }^{[16]}$. Especially in China, there is virtually nothing known about coping strategies and their relationship with self-esteem, individual and environmental factors among nursing students. Nursing requires very good mental health and effective coping strategies. Nursing students' coping strategies will influence their physical and mental health, and the quality of health services that they deliver. Therefore, studying the coping strategies of nursing students and related factors are very important for early intervention. To our knowledge, this is the first study of coping strategies of Chinese female nursing students. The objectives of the study were:

- To identify different coping strategies among Chinese female students in different years of nursing school.

- To determine the relationship between coping and self-esteem of female nursing students.

- To determine individual factors that influence coping strategies of female nursing students.

\section{Subjects and methods}

In 2010, a cross-sectional survey was undertaken among female nursing students in Xi'an, China. 


\subsection{Sample and procedure}

A cluster and stratified sampling method was used to recruit study participants. First, three nursing schools were selected from nine nursing schools in Xi'an by random numbers. Second, each year of nursing school was determined as a stratum. Twenty-five percent of nursing students from the first to third years of study were randomly recruited according to students’ ID number.

Sample inclusion criteria were: female nursing students aged 14 years or older from the first to third years of school.

The survey was conducted in December 2010. Trained investigators, who worked in the nursing departments, carried out surveys using a structured questionnaire in selected class sessions. Under uniform instruction, nursing students completed the questionnaires.

\subsection{Ethical issues}

The study was approved by the ethics committee of Fourth Military Medical University. School visits were made to explain the objectives of the study, participation was voluntary, and participation would not affect respondents' education. Anonymity and confidentiality was assured for all respondents. All of the randomly sampled students were informed of the study purpose and their right to withdraw, and written consents were obtained from them.

\subsection{I nstruments}

The participants were given self-report questionnaires including the Simplified Coping Style Questionnaire, the Self-Esteem Scale and the Personal Data Form.

\subsubsection{The simplified coping styles questionnaire (CSQ)}

CSQ is a two-scale and 20-item questionnaire, developed by Xie ${ }^{[17]}$. The coping styles in this questionnaire were classified into two dimensions: positive coping style and negative coping style. Positive coping consists of 12 items, such as focusing on the positive aspects and trying to find different resolutions of the problem. Negative coping consists of 8 items, such as the use of tobacco and alcohol to deal with situations or trying to forget the problem. Questions are rated on a four-point scale, ranging from 0 to 3 ( $0=$ never use, 1 = seldom use, $2=$ often use, $3=$ always use). The higher mean score of each dimension indicates frequent usage of this coping style. The CSQ has adequate reliability, its test-retest correlation coefficient was 0.89 , and the internal consistency measured by Cronbach's alpha was found to be $0.78^{[17]}$.

\subsubsection{The self-esteem scale (SES)}

SES measures the participants' level of self-esteem. The scale consists of 10 items, was developed by Rosenberg in 1965, and was translated into Chinese by $\mathrm{Ji}^{[18]}$. Each item is scored on a four-point scale from 1 ("strongly agree") to 4 ("strongly disagree”). Scoring is accomplished by summing responses to the questions. A cumulative score is derived, and the higher the score the higher one's self-esteem. The instrument has been found to have adequate reliability, its test-retest correlation coefficient was 0.89 , and internal consistency measured by Cronbach's alpha was found to be $0.77^{[19]}$.

\subsubsection{The personal data form}

This 50-item self-evaluation questionnaire elicits demographic, individual and environmental characteristics such as age, gender, year in school, attitude to nursing, physical health status, study and employment stress, environmental adaptation, educational expectation, romantic and interpersonal relationships, self-fulfilment and satisfaction, psychological consultation, and frequency of surfing on the internet. Most of the questions were assessed on a dummy coded scale (response was coded 0 for a no response and 1 for a yes response).

\subsubsection{Definition of some individual factors}

Having a sense of self-fulfillment and satisfaction was defined as one's potential development, expected fulfillment and self-satisfaction. 
Help-seeking behavior of an individual was defined as a psychological consultation at least two times in the past year.

Having a close friendship was defined as having at least a friend to talk with about getting through one’s troubles.

\subsection{Data analysis}

Data was input into an Epidata3.1a database. The SPSS statistics software package (version 16.0) was used for all data analysis. Categorical data of the study population was reported as frequencies, and the continuous data as means with standard deviations. The mean scores of positive and negative coping among nursing students were compared using t-test. Comparisons of coping strategies and self-esteem among students in different years of nursing school were performed using one-way ANOVA. If statistical difference was found between the groups in one-way ANOVA, then the LSD test was used to analyze the data further.

To assess the contributions of self-esteem, individual and environmental factors to coping strategies, multiple linear regression analysis was performed, positive or negative coping score as the dependent variable, and items including age, year in school, level of self-esteem, attitude to nursing, physical health status, study and employment stress, environmental adaptation, educational expectation, romantic and interpersonal relationship, self-fulfillment and satisfaction, help-seeking behavior, and frequency of surfing on the internet independent variables. Variables were selected for inclusion in the multivariable models if they were at least marginally significant $(P \leqslant 0.05)$.

\section{Results}

\subsection{Survey response and demographics characteristic}

The original sample contained 700 study participants. Questionnaires were not completed for 14 participants, so the data of 686 participants was available for a response rate of 98.0\%. All the participants were female (100\%).

The mean age was 15.89 years ( $\mathrm{SD}=1.73$, range $=14-18$ ). The participants in first to third year of nursing school was 222 (32.4\%), 264 (38.5\%) and 200 (29.1\%), respectively.

\subsection{Coping styles and self-esteem among female nursing students in different years of school}

Table 1 shows the comparison of positive and negative coping scores among female nursing students. There was a statistically significant difference between them $(P<0.01)$.

Table 1. Comparison of positive and negative coping scores among female nursing students

\begin{tabular}{llllll}
\hline variables & $\boldsymbol{n}$ & Mean & $\boldsymbol{S D}$ & $\boldsymbol{t}$ & $\boldsymbol{P}$ \\
\hline positive coping & 686 & 1.84 & 0.46 & 22.698 & $<0.001$ \\
negative coping & 686 & 1.30 & 0.53 & & \\
\hline
\end{tabular}

Differences between coping styles by year in nursing school are shown in Table 2. The use of positive coping in third year nursing students was significantly less than in first and second year students (both $P<0.05$ ). There were no significant differences in the use of negative coping and self-esteem between nursing students in the different years of school $(P>0.05)$, but the score of negative coping and self-esteem was lower for the third year students. 
Table 2. Comparison of coping styles and self-esteem among nursing students in different years of school

\begin{tabular}{|c|c|c|c|c|c|c|c|}
\hline Variables & $\begin{array}{l}\text { first-year } \\
(n=222) \\
\text { Mean SD }\end{array}$ & $\begin{array}{l}\text { second-year } \\
(n=264) \\
\text { Mean SD }\end{array}$ & $\begin{array}{l}\text { third-year } \\
(\mathrm{n}=200) \\
\text { Mean SD }\end{array}$ & $\boldsymbol{P}$ & $P_{1}$ & $P_{2}$ & $\boldsymbol{P}_{3}$ \\
\hline positive coping & 1.880 .46 & 1.860 .42 & 1.760 .52 & $0.018^{*}$ & 0.504 & $0.030 *$ & $0.007 * *$ \\
\hline negative coping & 1.290 .55 & $1.34 \quad 0.49$ & $1.26 \quad 0.58$ & 0.263 & 0.309 & 0.110 & 0.557 \\
\hline self-esteem & $\begin{array}{ll}2.87 & 0.39\end{array}$ & 2.850 .37 & $2.80 \quad 0.38$ & 0.165 & 0.564 & 0.172 & 0.064 \\
\hline
\end{tabular}

Note. $P_{1}$ : between years one and two; $P_{2}:$ between years two and three; $P_{3}$ : between years one and three. $* P \leqslant 0.05, * * P \leqslant 0.01$

\subsection{Related factors of positive and negative coping of female nursing students}

Multiple linear regression analysis suggested that there was no significant relationship between age, year in school and positive coping. Table 3 shows the results for predictors of positive coping. Those factors significantly related to positive coping were higher levels of self-esteem, good interpersonal relationships, enough free time for study alone, self-fulfillment and satisfaction, not adapting oneself to new study methods, having no close friendships, help-seeking behavior of an individual, good physical health in the past year, and having good relationships with parents $(P<0.05$ or $P<0.01)$.

Table 3. Multiple linear regression results for prediction of positive coping $(\mathrm{n}=686)$

\begin{tabular}{|c|c|c|c|c|}
\hline Variables & $\begin{array}{l}\text { Unstandardized } \\
\text { coefficients } \\
\text { B }\end{array}$ & $\begin{array}{l}\text { Standardized } \\
\text { coefficients } \\
\text { Beta }\end{array}$ & $t$ & $\boldsymbol{P}$ \\
\hline higher level of self-esteem & 0.371 & 0.253 & 6.494 & $0.000^{* *}$ \\
\hline having good interpersonal relationship & 1.843 & 0.114 & 3.215 & $0.001^{* *}$ \\
\hline having enough free time for study alone & 0.770 & 0.096 & 2.633 & $0.009^{* *}$ \\
\hline $\begin{array}{l}\text { having a sense of self-fulfillment and } \\
\text { satisfaction }\end{array}$ & 0.953 & 0.096 & 2.594 & $0.010^{* *}$ \\
\hline adaptation to new study methods & -0.887 & -0.090 & -2.474 & $0.014^{*}$ \\
\hline having no close friends & -0.931 & -0.098 & -2.659 & $0.008^{* *}$ \\
\hline $\begin{array}{l}\text { help-seeking behavior of an } \\
\text { individual }\end{array}$ & 0.773 & 0.078 & 2.112 & $0.035 *$ \\
\hline physical health in the past year & 0.912 & 0.088 & 2.400 & $0.017^{*}$ \\
\hline having good relationship with parents & 1.107 & 0.146 & 3.200 & $0.001^{* *}$ \\
\hline
\end{tabular}

$* P \leqslant 0.05, * * P \leqslant 0.01$

Table 4 shows predictors of negative coping, including problems in romantic relationship, worrying about examinations, bad relationships with parents, worrying about job assignments after graduation, being misunderstood, and frequent internet surfing $(P<0.05$ or $P<0.01)$. 
Table 4. Multiple linear regression results for prediction of negative coping $(\mathrm{n}=686)$

\begin{tabular}{lllll}
\hline Variables & $\begin{array}{l}\text { Unstandardized } \\
\text { coefficients } \\
\boldsymbol{B}\end{array}$ & $\begin{array}{l}\text { Standardized } \\
\text { coefficients } \\
\text { Beta }\end{array}$ & $\boldsymbol{t}$ & $\boldsymbol{P}$ \\
\hline having problems in romantic relationship & 1.626 & 0.205 & 5.373 & $0.000^{* *}$ \\
worry about examinations & 0.683 & 0.090 & 2.425 & $0.016^{*}$ \\
having bad relationship with parents & 0.498 & 0.085 & 2.320 & $0.021^{*}$ \\
worry about job assignment after graduation & -0.565 & -0.085 & -2.280 & $0.023^{*}$ \\
feeling misunderstood & 0.649 & 0.078 & 2.080 & $0.038^{*}$ \\
frequent surfing internet & 0.537 & 0.081 & 2.183 & $0.029^{*}$ \\
\hline
\end{tabular}

${ }^{*} P \leqslant 0.05,{ }^{* *} P \leqslant 0.01$

\section{Discussion}

The current study indicates that Chinese female nursing students more often used positive than negative coping. This result was contrasted with an earlier report that females endorsed an emotional or negative coping than positive coping style ${ }^{[6]}$. A possible explanation is that nursing is a demanding and stressful profession ${ }^{[20]}$, which requires effective coping strategies.

Coping strategies are defined as a set of behavioral and cognitive responses to stress. This study showed there was a significant difference in coping styles based upon the different years in nursing school. Third year nursing students used less positive coping in response to stresses than first or second year students. Although there was no significant difference in negative coping by year in nursing school, the score of negative coping was also lower for the third year students, which means the students in the third year also used less negative coping. The possible reason was that compared with students in the first and second years of nursing school, students in the third year tend to be confronted with greater pressure from their studies, society and employment ${ }^{[21]}$. Once they were in the face of stressors, they may be more cautious use coping strategies because they are afraid to use it in a wrong way and make mistakes. The results indicates that third year students should be paid more attention to in the development of coping strategies.

Previous studies showed that positive coping in adolescents was associated with a higher level of self-esteem ${ }^{\text {[13] }}$. The present study confirms the results of those previous studies. A strong relationship between a higher level of self-esteem, self-fulfillment and satisfaction, and positive coping was found among female nursing students. Nursing students with a higher level of self-esteem, self-fulfillment and satisfaction, in turn, may be more inclined to use positive coping. Therefore, it is important to cultivate effective coping strategy among nursing students. Lower scores for the third year students on positive and negative coping as well as on self-esteem were found in this study. This result indicated that the teaching strategies that promote the self-esteem may be useful for helping nursing students develop effective coping styles. Further study on this aspect needs to be made in the future.

Interpersonal relationship was found to be important for the development of nursing students in our previous study ${ }^{[22]}$. With the policy of "one family, one child" in China, more and more nursing students are the only child in their family. When nursing students are confronted with stress, family and social support will be of benefit to them. The present study showed positive coping was significantly associated with higher quality interpersonal relationships. For example, with good relationship with parents and classmates, nursing students may be encouraged to develop positive coping. 
Conversely, isolation, a lack of close friendships and the self-perception of being misunderstood were found to be positively associated with negative coping.

Coping with study and employment stress have long been recognized as a challenge for nursing students. Surveys of behavior problems and psychological symptoms in Chinese nursing students have reported that study stress was the most significant predictor of mental health problems ${ }^{[23-25]}$. In the present study, study and employment stress and coping styles were significantly related. Having enough free time for study alone was one of the most important factors of positive coping. Conversely, not having adapted oneself to new study methods was negatively associated with coping. Worrying about examinations and job assignment after graduation was associated with negative coping.

The development of romantic relationships was common in nursing students. Not much research to date has dealt with specific stressors and coping styles in romantic experiences. The current study found that those female nursing students having problems in romantic relationship were more inclined to use a negative coping style.

Previous studies reported that positive coping correlated negatively with indicators of health problems and health risk behaviors, while negative coping strategy correlated positively with these domains ${ }^{[26-28]}$. The current study supported the earlier observations. Physical health and help-seeking behavior of an individual were positively related to positive coping. There was no significant correlation between physical health or help-seeking behavior of an individual and negative coping. The current study showed that female nursing students who frequently surfed on the internet tended to use negative coping. As technology has continued its explosive growth, the internet has become and will continue to be a large part of students' lives as well as has a negative effect on students' learning and daily lives. When faced with stressors, they maybe tend to seek help on line and use negative coping. The result indicates those students who frequently surfed on the internet should be give guide on coping strategies.

There were some limitations to this study. First, the study was performed in Xi'an, China. There may be regional factors that influence the coping strategies of nursing students, so the ability to generalize the results of the present study to a larger population has to be considered. Secondly, the study was a cross-sectional design and the association between individual and environmental factors, self-esteem and coping strategies was reported. However, the association can only give a clue to causation. Some prospective and longitudinal studies such as a trial to test whether training in coping strategies can alter health are required in future.

Despite the limitation, our study has a number of strengths. Unlike most previous reports dealing primarily with the stress and coping strategies among nursing students in clinical practice, this study explores the use of coping strategies in different years of nursing school and their related factors in China. It provides important data on the impact of self-esteem, individual and environmental factors on coping strategies, which will be very important for early intervention of the development of coping strategies and mental health among nursing students.

\section{Conclusion}

The study showed different coping strategies and the important relationship between self-esteem, individual and environmental factors and coping strategies among Chinese female nursing students in different years of school. The findings suggested that the teaching strategies that promote the self-esteem and pay more attention to students' individual and environmental factors will be useful for helping nursing students develop effective coping styles.

\section{Acknowledgement}

This study was instructed by epidemiology and statistics department of Fourth Military Medical University. We thank the staff of this department and the three public nursing schools for their assistance with instrumentation and fieldwork. 


\section{References}

[1] Carver, C.S., Pozo, C., Harris, S.D., Noriega, V., Scheier, M.F., Robinson, D.S., et al. How coping mediates the effect of optimism and distress: a study of women with early stage breast cancer. Journal of Personality and Social Psychology. 1993; 65(2): 375-390. PMid:8366426 http://dx.doi.org/10.1037/0022-3514.65.2.375

[2] Lewis, R., Frydenberg, E. Concomitants of failure to cope: what we should teach adolescents about coping. British Journal of Educational Psychology. 2002; 72(3): 419-431. PMid:12396314 http://dx.doi.org/10.1348/000709902320634483

[3] Penley, J.A, Tomaka, J., Wiebe, J.S. The association of coping to physical and psychological health outcomes: a meta-analytic review. J Behav Med. 2002; 25(6):551-603. PMid:12462958 http://dx.doi.org/10.1023/A:1020641400589

[4] Gibbons, C., Dempster, M., Moutray, M. Stress, coping and satisfaction in nursing students. Journal of Advanced Nursing. 2011; 67(3): 621-632. PMid:21077931 http://dx.doi.org/10.1111/j.1365-2648.2010.05495.x

[5] Gibbons, C. Stress, coping and burn-out in nursing students. International Journal of Nursing Studies. 2010; 47(10): 1299-1309. PMid:20359710 http://dx.doi.org/10.1016/j.ijnurstu.2010.02.015

[6] Folkman, S., Lazarus, R. S. An analysis of coping in a middle-aged community sample. Journal of Health and Social Behavior. 1980; 21(3): 219-239. PMid:7410799 http://dx.doi.org/10.2307/2136617

[7] Houtman, I. L. D. Personal coping resources and sex differences. Personality and Individual Differences. 1990; 11(1): 53-63. http://dx.doi.org/10.1016/0191-8869(90)90168-Q

[8] The Morris Rosenberg Foundation. The Rosenberg Self-Esteem Scale [Internet]. Retrieved February 6, 2006 from University of Maryland, College Par, Department of Sociology. Available from: http://www.bsos.umd.edu/socy/grad/socpsy rosenberg.html.

[9] Kling, K.C., Hyde, J.S., Showers, C.J., Buswell, B.N. Gender differences in self-esteem: A meta analysis. Psychological Bulletin. 1999; 125(4): 470-500. PMid:10414226 http://dx.doi.org/10.1037/0033-2909.125.4.470

[10] Strauss, R.S., Rodzilsky, D., Burack, G., Colin, M. Psychosocial correlates of physical activity in healthy children. Archives of Pediatrics and Adolescent. 2001; 155(8): 897-902.

[11] Trzesniewski, K.H., Donnellan, M.B., Robins, R.W. Stability of self-esteem across the life span. Journal of Personality and Social Psychology. 2003; 84(1): 205-220. PMid:12518980 http://dx.doi.org/10.1037/0022-3514.84.1.205

[12] Strong, W.B., Malina, R.M., Blimkie, C.J., Daniels, S.R., Dishman, R.K., Gutin, B., et al. Evidence based physical activity for school-age youth. The Journal of Pediatrics. 2005; 146(6): 732-737. PMid:15973308 http://dx.doi.org/10.1016/j.jpeds.2005.01.055

[13] Mullis, R.L., Chapman, P. Age, gender, and self-esteem differences in adolescent coping styles. The Journal of Social Psychology. 2000; 140(4): 539-541. PMid:10981384 http://dx.doi.org/10.1080/00224540009600494

[14] Renk, K., Creasey, G. The relationship of gender, gender identity, and coping styles in late adolescents. Journal of Adolescence. 2003; 26(2): 159-168. http://dx.doi.org/10.1016/S0140-1971(02)00135-5

[15] Schreuder, J.A., Roelen, C.A., Groothoff, J.W., Van der Klink, J.J., Magerøy, N., Pallesen, S., et al. Coping styles relate to health and work environment of Norwegian and Dutch hospital nurses: A comparative study. Nursing Outlook. 2011; In Press.

[16] Chang, E.M., Daly, J.W., Hancock, K.M., Bidewell, J., Johnson, A., Lambert, V.A., et al. The relationships among workplace stressors, coping methods, demographic characteristics, and health in Australian nurses. Journal of Professional Nursing. 2006; 22(1): 30-38. PMid:16459287 http://dx.doi.org/10.1016/j.profnurs.2005.12.002

[17] Xie, Y.N. Simplified coping style questionnaire. Chinese Mental Health Journal. 1999; suppl: 122-124.

[18] Ji, Y.F., Yu, X. Self-esteem scale. Chinese Mental Health Journal. 1999; suppl: 319-320.

[19] Gan, X., Jin, X. Study on the association between SES, social support and subjective well-being. Journal of Qiqihar Vocational College. 2008; 24(2): 85-89.

[20] Watson, R., Dreary, I., Thompson, D., Li, G. A study of stress and burnout in nursing students in Hong Kong: a questionnaire survey. International Journal of Nursing Studies. 2008; 45: 1534-1542. PMid:18241870 http://dx.doi.org/10.1016/j.ijnurstu.2007.11.003

[21] Feng, W.H., Wang, A.Y., Wang, H., Liu, K.K. An analysis of pressure sources among nurse graduate students in practice and its countermeasures. Chinese Nursing Management. 2006; 6(7): 45-47.

[22] Ni, C.P., Liu, X.W., Hua, Q.Z., Lv, A.L., Wang, B., Yan, Y.P. Relationship between coping self-esteem, individual factors and mental health among Chinese nursing students: A matched case-control study. Nurse Education Today. 2010; 30(4): $338-343$. PMid:19800152 http://dx.doi.org/10.1016/j.nedt.2009.09.003

[23] Liu, X. Cigarette smoking, life stress, and behavioral problems in Chinese adolescents. Journal of Adolescent Health. 2003; 33(6): 189-192. http://dx.doi.org/10.1016/S1054-139X(03)00020-X 
[24] Liu, X., Kurita, H., Uchiyama, M., Okawa, M., Liu, L., Ma, D. Life events, locus of control, and behavioral problems among Chinese adolescents, Journal of Clinical Psychology. 2000; 56(12): 1565-1577. http://dx.doi.org/10.1002/1097-4679(200012)56:12<1565::AID-7>3.0.CO;2-U

[25] Liu, X., Kurita, H., Guo, C., Miyake, Y., Ze, J., Cao, H. Prevalence and risk factors of behavioral and emotional problems among Chinese children aged 6 through 11 years, Journal of the American Academy of Child and Adolescent Psychiatry. 1999; 38(6): 708-715. http://dx.doi.org/10.1097/00004583-199906000-00018

[26] Holahan, C.J., Moos, R. H. Life stressors, personal and social resources, and depression: A 4-year structural model. Journal of Abnormal Psychology. 1991; 100(1): 31-38. PMid:2005268 http://dx.doi.org/10.1037/0021-843X.100.1.31

[27] Frydenberg, E., Lewis, R. Relations among well-being, avoidant coping, and positive coping in a large sample of Australian adolescents. Psychological Reports. 2009; 104(3): 745-758. PMid:19708401 http://dx.doi.org/10.2466/pr0.104.3.745-758

[28] Steiner, H., Erickson, S.J., Hernandez, N.L., Pavelski, R. Coping styles as correlates of health in high school students. Journal of Adolescent Health. 2002; 30(5): 326-335. http://dx.doi.org/10.1016/S1054-139X(01)00326-3 